\title{
Intracranial Stenosis: Impact of Randomized Trials on Treatment Preferences of US Neurologists and Neurointerventionists
}

\author{
Tanya N. Turan $^{a}$ George Cotsonis ${ }^{b}$ Michael J. Lynn ${ }^{b}$ Rahim H. Wooley \\ Seegar Swanson ${ }^{b}$ Janice E. Williams ${ }^{c}$ Barney J. Stern ${ }^{d}$ Colin P. Derdeyn ${ }^{\mathrm{e}}$ \\ David Fiorella $^{f}$ Marc I. Chimowitz ${ }^{a}$

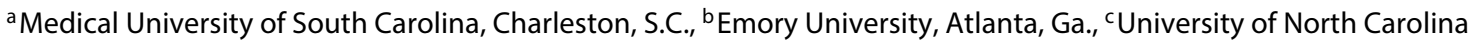 \\ at Chapel Hill, Chapel Hill, N,C., ${ }^{d}$ University of Maryland, Baltimore, Md., 'Washington University, St. Louis, Mich., and \\ fState University of New York at Stony Brook, Stony Brook, N.Y., USA
}

\section{Key Words}

Intracranial stenosis · Survey - Cerebral arteries .

Treatment practices

\begin{abstract}
Background and Purpose: Medical and endovascular treatment options for stroke prevention in patients with symptomatic intracranial stenosis have evolved over the past several decades, but the impact of 2 major multicenter randomized stroke prevention trials on physician practices has not been studied. We sought to determine changes in US physician treatment choices for patients with intracranial atherosclerotic stenosis (ICAS) following $2 \mathrm{NIH}$-funded clinical trials that studied medical therapies (antithrombotic agents and risk factor control) and percutaneous transluminal angioplasty and stenting (PTAS). Methods: Anonymous surveys on treatment practices in patients with ICAS were sent to physicians at 3 time points: before publication of the $\mathrm{NIH}$ funded Warfarin-Aspirin Symptomatic Intracranial Disease (WASID) trial (pre-WASID survey, 2004), 1 year after WASID publication (post-WASID survey, 2006) and 1 year after the publication of the $\mathrm{NIH}$-funded Stenting and Aggressive
\end{abstract}

\section{KARGER}

E-Mail karger@karger.com

www.karger.com/ced
Medical Management for Preventing Recurrent Stroke in Intracranial Stenosis (SAMMPRIS) trial (post-SAMMPRIS survey, 2012). Neurologists were invited to participate in the preWASID survey $(n=525)$. Neurologists and neurointerventionists were invited to participate in the post-WASID $(n=$ $598)$ and post-SAMMPRIS $(n=2,080)$ surveys. The 3 surveys were conducted using web-based survey tools delivered by E-mail, and a fax-based response form delivered by E-mail and conventional mail. Data were analyzed using the $x^{2}$ test. Results: Before WASID, there was equipoise between warfarin and aspirin for stroke prevention in patients with ICAS. The number of respondents who recommended antiplatelet treatment for ICAS increased across all 3 surveys for both anterior circulation (pre-WASID $=44 \%$, post-WASID $=85 \%$, post-SAMMPRIS $=94 \%$ ) and posterior circulation (preWASID $=36 \%$, post-WASID $=74 \%$, post-SAMMPRIS $=83 \%$ ). The antiplatelet agent most commonly recommended after WASID was aspirin, but after SAMMPRIS it was the combination of aspirin and clopidogrel. The percentage of neurologists who recommended PTAS in $>25 \%$ of ICAS patients increased slightly from pre-WASID (8\%) to post-WASID surveys $(12 \%)$, but then decreased again after SAMMPRIS (6\%). The percentage of neurointerventionists who recommended (c) 2014 S. Karger AG, Basel

1015-9770/14/0373-0203\$39.50/0
Tanya N. Turan, MD, MS

MUSC Stroke Program, Department of Neurosciences

Medical University of South Carolina

Charleston, SC 29425 (USA)

E-Mail turan@musc.edu 
PTAS in $>25 \%$ of ICAS patients decreased from post-WASID $(49 \%)$ to post-SAMMPRIS surveys (17\%). Conclusions: The surveyed US physicians' recommended treatments for ICAS differed over the 3 survey periods, reflecting the results of the $2 \mathrm{NIH}$-funded clinical trials of ICAS and suggesting that these clinical trials changed practice in the USA.

(C) 2014 S. Karger AG, Basel

\section{Introduction}

Intracranial atherosclerotic stenosis (ICAS) causes $8-10 \%$ of ischemic strokes in the USA [1] and is one of the most common causes of stroke worldwide [2]. Despite the high prevalence and high risk of recurrent stroke associated with ICAS, optimal treatment for this disease is still evolving. Over a decade ago, physician preferences regarding antithrombotic and endovascular treatment of ICAS were largely based on retrospective studies [3] and expert opinion [4], but since then, 2 large randomized trials have compared treatment strategies for this disease. First, the Warfarin-Aspirin Symptomatic Intracranial Disease (WASID) trial compared aspirin versus warfarin among patients with symptomatic 50-99\% intracranial stenosis and found that aspirin was safer and as effective as warfarin for the prevention of stroke and vascular death in patients with ICAS [5]. More recently, the Stenting and Aggressive Medical Management for Prevention of Recurrent Stroke in Intracranial Stenosis (SAMMPRIS) trial compared aggressive medical management versus aggressive medical management plus percutaneous transluminal angioplasty and stenting (PTAS) among patients with symptomatic $70-99 \%$ stenosis and found a high rate of periprocedural stroke after PTAS and a lower than expected rate of stroke on aggressive medical therapy [6]. The impact of these large randomized trials on clinical practice has not been quantified. Therefore, we sought to determine the impact of the results of these studies on treatment choices of US physicians managing patients with ICAS by surveying physicians before and after the publications of the WASID and SAMMPRIS trials.

\section{Methods}

Anonymous surveys of physician treatment choices were conducted at the following times: (1) pre-WASID: prior to publication of WASID results (2004); (2) post-WASID: 1 year after publication of the WASID results (2006), and (3) post-SAMMPRIS: approximately 1 year after publication of the SAMMPRIS trial results (2012).
Pre-WASID Survey

The pre-WASID survey was conducted using a written questionnaire, sent by E-mail or conventional mail (if no E-mail). The survey was sent to neurologists and included WASID investigators $(\mathrm{n}=90)$ and American Academy of Neurology Stroke Section members $(n=435)$, and it was available for 8 weeks. One reminder was sent. Completed questionnaires were faxed to the WASID Datafax server. The survey included 15 multiple-choice questions (online suppl. appendix A; for all online suppl. material, see www. karger.com/doi/10.1159/000358120) on the following topics: physician's practice setting, experience treating stroke, preferred antithrombotic agent for ICAS, willingness to change practice based on the WASID results, current use of PTAS for ICAS.

\section{Post-WASID Survey}

The post-WASID survey was administered using an Internetbased survey tool (www.questionpro.com). The survey was sent to neurologists, including WASID investigators and American Academy of Neurology Stroke Section members with available E-mail addresses $(n=233)$, and neurointerventionists who were American Society of Interventional and Therapeutic Neuroradiology members with available E-mail addresses $(n=365)$, and it was available for 8 weeks. Not all E-mail addresses were valid, but attempts were made to ascertain the correct contact information and remove duplicates. E-mail notification of the request to complete the survey and a link to the survey were sent, and one reminder E-mail was sent.

The post-WASID survey included multiple-choice questions (online suppl. appendix B) on the same topics as the pre-WASID survey, but also included questions that asked respondents to choose the maximum 2-year rate of stroke in the territory of the symptomatic intracranial artery among patients treated with PTAS that would result in PTAS becoming their treatment of choice for the following 2-year stroke rates on medical therapy: $25,20,16$ and $12 \%$. The response options reflected a $25,33,40$, 50 and $60 \%$ relative risk reduction (RRR) from PTAS or 'medical therapy would remain my treatment regardless of stenting rate'.

\section{Post-SAMMPRIS Survey}

The post-SAMMPRIS survey was administered using the Internet-based Research and Electronic Data Capture (REDCap) survey tool [7]. The survey was sent to neurologists from previous E-mail lists and American Academy of Neurology Stroke Section members with available E-mail addresses $(n=1,400)$ and neurointerventionists from previous survey E-mail lists and members of the Society of Vascular Interventional Neurologists and Society of Neurointerventional Surgeons $(n=680)$, and it was available for 1 month. Attempts were made to ascertain the correct contact information and remove duplicate E-mails. E-mail notification of the request to complete the survey and a link to the survey were sent, and one reminder E-mail was sent.

The post-SAMMPRIS survey included multiple-choice questions (online suppl. appendix C) on the topics of the prior surveys, but also included questions about the definition of 'failure of medical therapy', factors that influence treatment with PTAS and the impact of SAMMPRIS on practice. Three questions asked respondents to choose the maximum 1-year rate of stroke in the territory of the symptomatic intracranial artery among patients treated with a 'new endovascular procedure' that would result in that procedure 
Table 1. Characteristics of the survey respondents

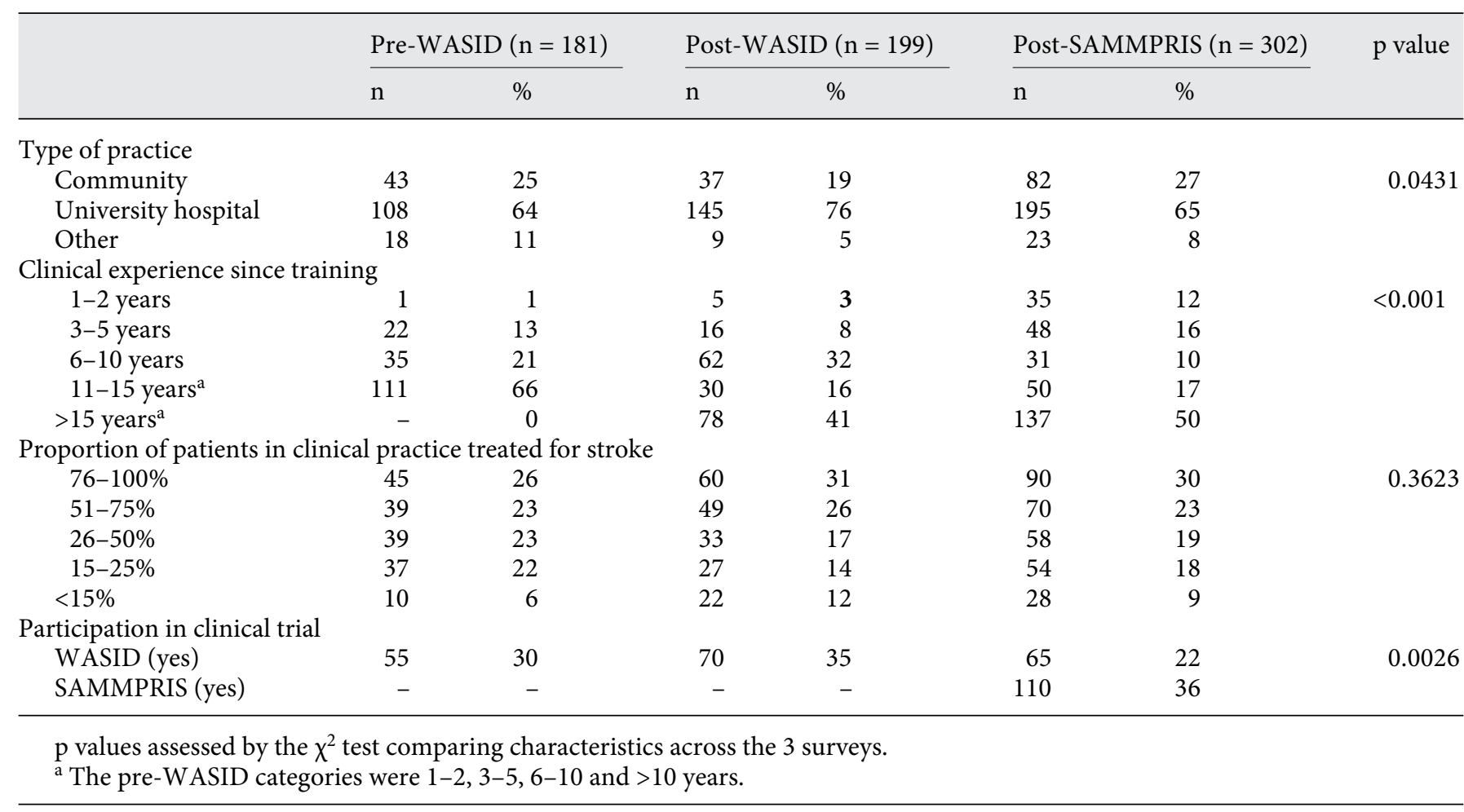

becoming their treatment of choice for the following 1-year stroke rates on aggressive medical therapy: 25,20 and $16 \%$. The response options reflected a 25, 33, 40, 50 and $60 \%$ RRR from the 'new endovascular procedure' or 'aggressive medical therapy would remain my treatment regardless'.

\section{Statistical Analysis}

Responses were characterized by standard descriptive statistics (i.e. percentages). Survey questions required categorical responses, with limited fields for 'other' answers. All comparisons between groups were done using $\chi^{2}$ analysis.

\section{Results}

The overall response rates for the surveys were: preWASID, 34\% (181/525); post-WASID, 33\% (199/598), and post-SAMMPRIS, 15\% (302/2,080). While the target groups were similar between the surveys, the number of respondents who completed more than one of the surveys is unknown due to anonymity. As shown in table 1 , in all surveys, the majority of respondents had university-based practices, were in practice 10 years or more, and at least $25 \%$ of their practice involved treating stroke patients. Respondents differed significantly in practice type and years in practice since training, with more university-based respondents in the post-WASID survey.

\section{Medical Management}

\section{Willingness to Change Practice}

In the pre-WASID survey, the majority of neurologists (91\%) indicated that if the 3-year stroke and vascular death rate was $30 \%$ on their preferred antithrombotic treatment, they would require a $20-33 \%$ RRR from the more effective antithrombotic agent to switch from their preferred agent, whether their preferred agent was warfarin or aspirin. Only $3.6 \%$ would continue to use warfarin, and $1.4 \%$ would continue to use aspirin regardless of the WASID results.

\section{Choice of Antithrombotic Medication}

The neurologists' preferred antithrombotic agent differed significantly between pre-WASID and post-WASID surveys for the treatment of both anterior circulation $(\mathrm{p}<$ $0.001)$ and posterior circulation $(\mathrm{p}<0.001)$ stenoses. As shown in figure 1 , the pre-WASID neurologists' preferred 


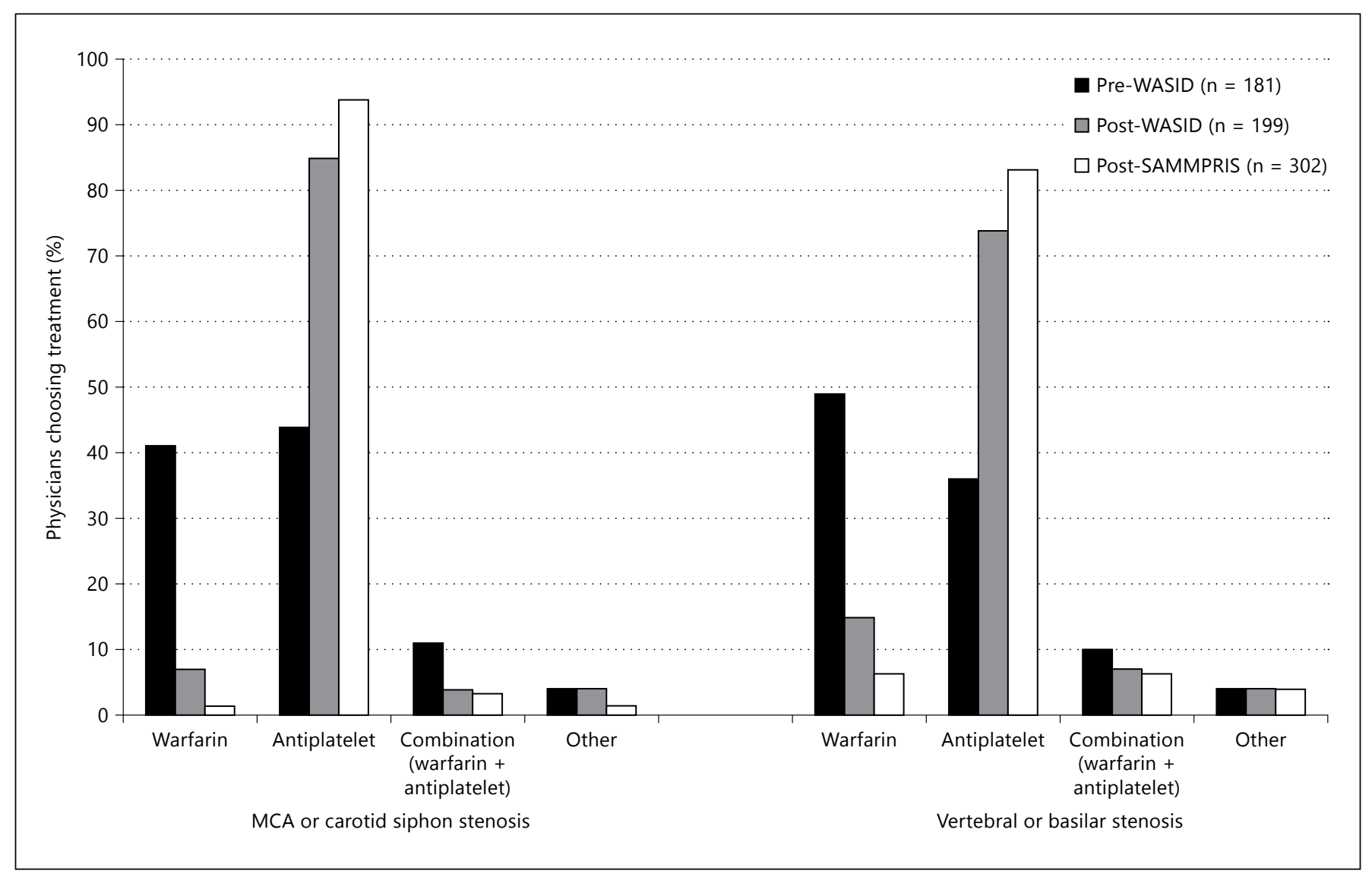

Fig. 1. Antithrombotic medication treatment preferences for symptomatic intracranial stenosis in 3 surveys.

antithrombotic treatment was equally divided between warfarin and antiplatelet agents for anterior circulation stenosis, but more neurologists preferred warfarin for posterior circulation stenosis. Compared to the postWASID respondents, more post-SAMMPRIS respondents preferred antiplatelet agents for stenosis in the anterior circulation ( 85 vs. $94 \%, \mathrm{p}=0.0017)$ and posterior circulation ( 74 vs. $83 \%, p=0.0145)$.

\section{Choice of Antiplatelet Agent}

As shown in table 2, the antiplatelet treatment most commonly preferred for ICAS after WASID was aspirin (44\% for anterior circulation, $43 \%$ for posterior circulation), whereas after SAMMPRIS it was the combination of aspirin and clopidogrel (45\% for anterior circulation, $43 \%$ for posterior circulation). The preferred dose of aspirin was $325 \mathrm{mg} /$ day in both the postWASID and post-SAMMPRIS surveys. The dose of aspirin used in the WASID trial $(1,300 \mathrm{mg} /$ day $)$ was preferred by only $11 \%$ of post-WASID respondents and virtually no post-SAMMPRIS respondents. In the postSAMMPRIS survey, the combination of aspirin and clopidogrel (which was used for 90 days after enrollment in SAMMPRIS) was recommended for 30, 90 days and indefinitely by 5,45 and $44 \%$ of respondents, respectively.

\section{Definition and Treatment of Patients on 'Maximal Medical Therapy'}

In the post-SAMMPRIS survey, the majority of respondents $(61 \%)$ considered 'maximal medical therapy' to include both 'use of antithrombotic treatment' and 'use of aggressive medical therapy to manage risk factors and achievement of SBP $<140$ and LDL $<70$, which were the risk factor targets in the SAMMPRIS trial [8]. Only $4 \%$ of respondents considered 'maximal medical therapy' to include only 'use of antithrombotic treatment'. For treatment recommendations in patients with symptomatic intracranial stenosis who had 'failed medical therapy', $50 \%$ of respondents reported that they 'as- 
Table 2. Post-WASID versus post-SAMMPRIS respondents' preferred antiplatelet agent regimen

\begin{tabular}{|c|c|c|c|c|}
\hline & post-WASID & post-SAMMPRIS & post-WASID & post-SAMMPRIS \\
\hline Aspirin & $75(44)$ & $93(34)$ & $66(43)$ & $95(38)$ \\
\hline Clopidogrel (Plavix) & $25(15)$ & $34(12)$ & $24(16)$ & $32(13)$ \\
\hline Aspirin and clopidogrel ${ }^{1}$ & $43(25)$ & $124(45)$ & $39(25)$ & $110(43)$ \\
\hline & \multicolumn{2}{|c|}{$\mathrm{p}<0.0001$} & \multicolumn{2}{|c|}{$\mathrm{p}<0.0001$} \\
\hline \multicolumn{5}{|c|}{ What dose of aspirin do you typically prescribe? } \\
\hline $81 \mathrm{mg} /$ day & $21(21)$ & $93(43)$ & $17(19)$ & $81(40)$ \\
\hline $325 \mathrm{mg} /$ day & $64(65)$ & $118(54)$ & $58(66)$ & $118(58)$ \\
\hline $650 \mathrm{mg} / \mathrm{day}$ & $2(2)$ & $1(<1)$ & $2(2)$ & $1(<1)$ \\
\hline $1,300 \mathrm{mg} /$ day & $11(11)$ & $1(<1)$ & $10(11)$ & $1(<1)$ \\
\hline
\end{tabular}

Results are expressed as numbers with percentages in parentheses.

${ }^{1}$ In the post-WASID survey, the selection choice was 'combination antiplatelet' and the most common combination selected was aspirin and clopidogrel. In the post-SAMMPRIS survey, the choice was 'combination aspirin + clopidogrel'.

sess for compliance and/or intensity medical therapy', whereas $45 \%$ 'recommend treatment with angioplasty or stenting'.

\section{Endovascular Treatment}

\section{Neurologist PTAS Recommendations}

The proportion of patients for whom the neurologists recommended PTAS significantly increased from the pre-WASID to the post-WASID survey $(\mathrm{p}<0.0001)$ and then decreased in the post-SAMMPRIS survey $(\mathrm{p}=$ 0.0135 ) to approximately pre-WASID levels, as shown in figure 2. The majority of neurologists recommended PTAS in less than $10 \%$ of their ICAS patients in all surveys.

\section{Neurointerventionist PTAS Recommendations}

In the post-WASID survey, about half of the neurointerventionists (51\%) reported that they recommended PTAS in $25 \%$ or less of their patients with ICAS, but in the post-SAMMPRIS survey $84 \%$ recommended PTAS in $25 \%$ or less, as shown in figure 2 . The proportion of neurointerventionists who recommended PTAS in over half of their patients with ICAS decreased from $29 \%$ in the post-WASID to $9 \%$ in the post-SAMMPRIS survey.

Intracranial Stenosis Treatment Preferences Survey

\section{Characteristics of Patients Selected for PTAS}

In the post-SAMMPRIS survey, the patient characteristics that were most commonly selected as influencing the decision to recommend PTAS were: symptoms attributed to hypoperfusion (81\%), severe stenosis (68\%), impaired collaterals (59\%) and recent symptoms (54\%).

\section{Required Risk-Reductions to Change Treatment of Choice}

Figure 3 shows the percentage of respondents in the post-WASID and post-SAMMPRIS surveys who selected each RRR for PTAS (post-WASID) or a 'new endovascular procedure' (post-SAMMPRIS) for the proposed 2-year rates of stroke in the territory of the symptomatic stenotic artery on medical treatment. For a stroke rate of $25 \%$ on medical therapy, the majority of post-WASID respondents required a minimum RRR of $33 \%$ - corresponding to a number needed to treat (NNT) of 13 - from PTAS to make PTAS their treatment of choice. As the stroke rate on medical therapy decreased, the RRR required increased. In the post-SAMMPRIS survey, the majority of respondents wanted an RRR of $40 \%$ (NNT of 10 for a stroke rate of $25 \%$ on medical therapy) from the 'new procedure', which is a higher RRR compared to the post-WASID survey respondents for the same event rate of $25 \%$ on medical therapy. For a medical therapy stroke rate of $16 \%$, the majority of post-WASID respondents required a minimum RRR of 


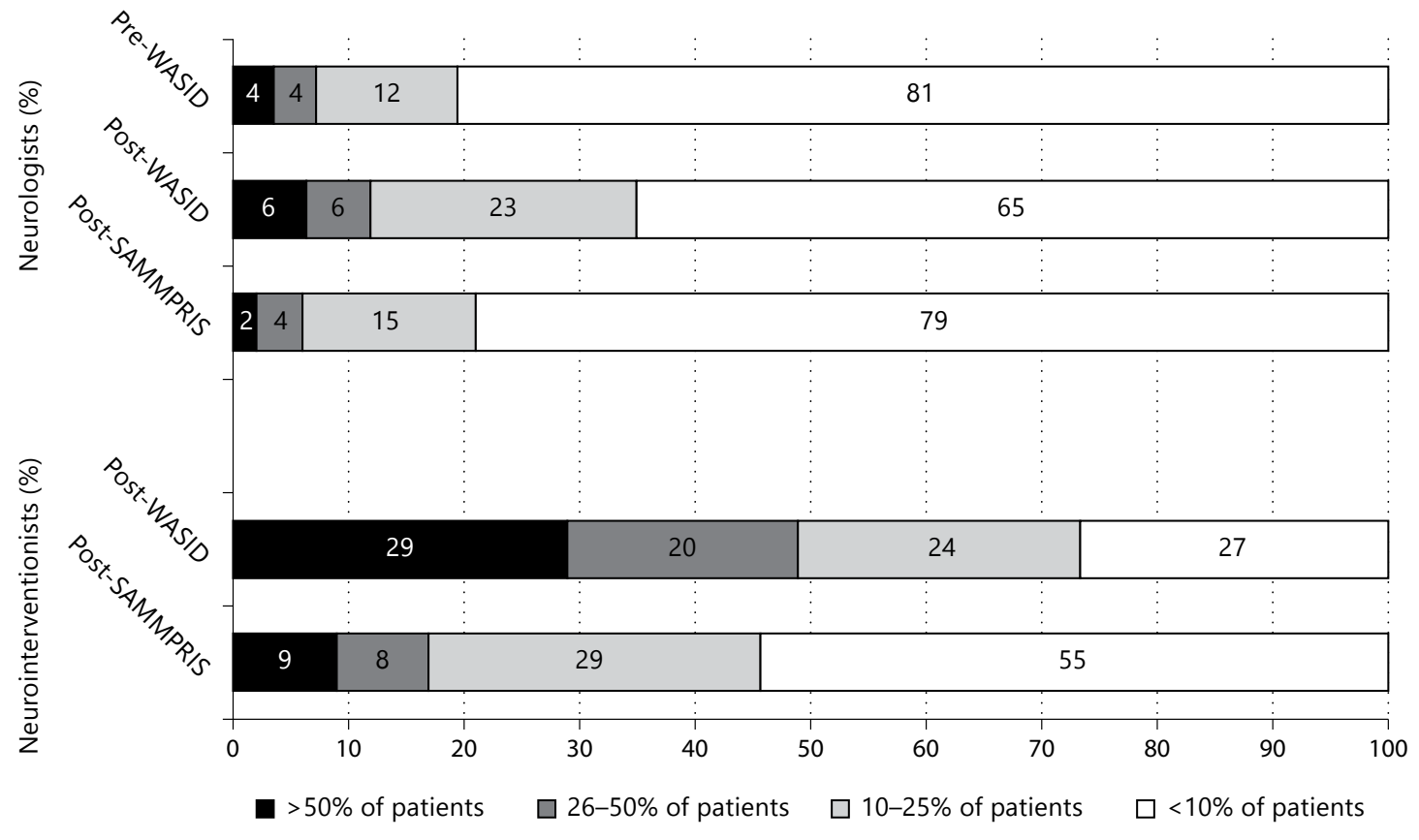

Fig. 2. Proportion of respondents who recommend angioplasty and stenting for a given proportion of patients with ICAS.

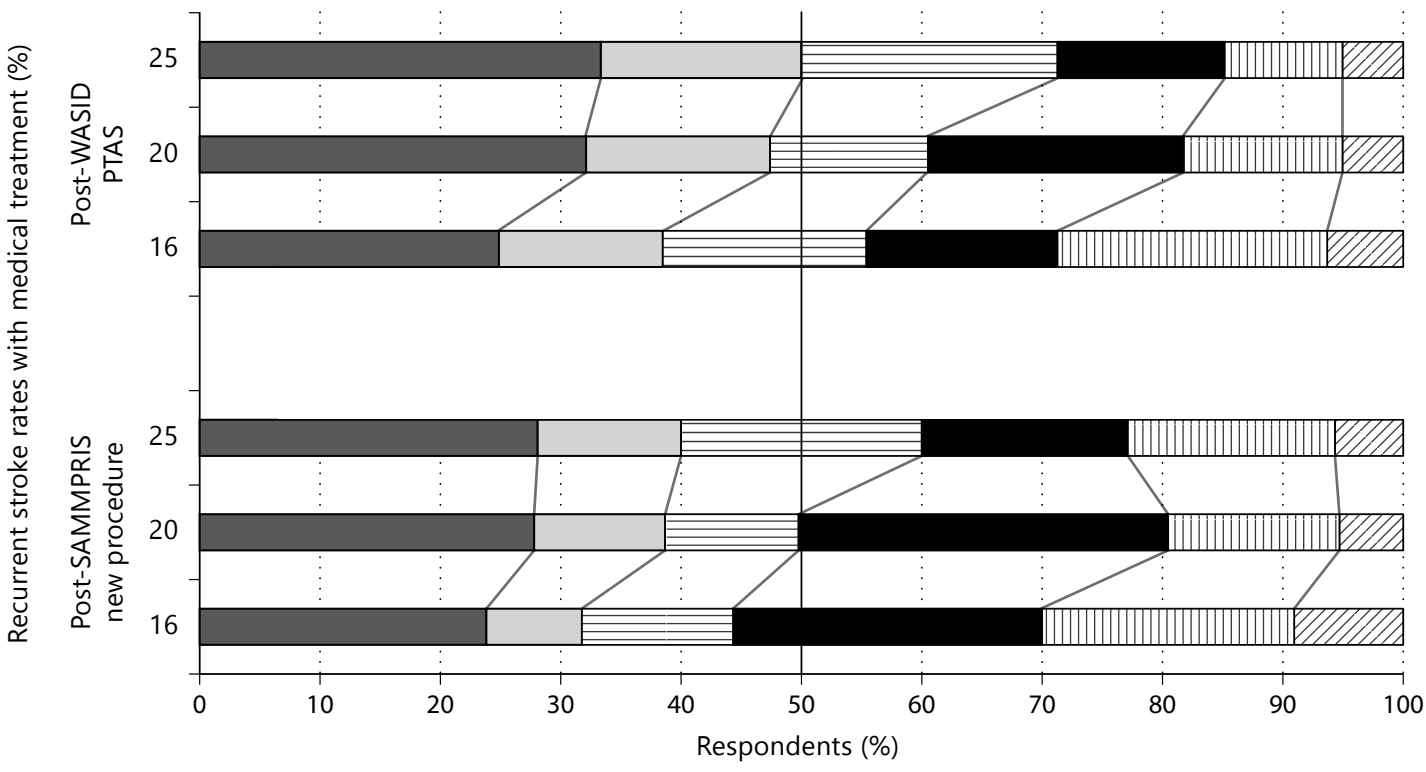

$25 \%$ RRR from procedure

$\square 33 \%$ RRR from procedure

$\boxminus 40 \%$ RRR from procedure

$50 \%$ RRR from procedure

$\square 60 \%$ RRR from procedure

$\square$ Medical therapy would remain treatment regardless of procedure rate

Fig. 3. RRR required by respondents to make the endovascular procedure the treatment of choice over medical therapy. Stroke rates: 2 -year rates in the post-WASID survey; 1-year rates in the post-SAMMPRIS survey. 
$40 \%$ (NNT of 17) from PTAS to make PTAS their treatment of choice. In the post-SAMMPRIS survey, the majority of respondents wanted an RRR of 50\% (NNT of 13 for a stroke rate of $16 \%$ on medical therapy) from the 'new procedure', which is also a higher RRR compared to the post-WASID survey respondents for the same event rate of $16 \%$ on medical therapy.

\section{Impact on Practice}

In the post-SAMMPRIS survey, 91\% (100/110) of respondents who participated in SAMMPRIS and $82 \%$ $(228 / 277)$ of overall respondents indicated that the SAMMPRIS results changed the way they managed patients with ICAS.

\section{Discussion}

Previous surveys have examined stroke prevention practices [9-11], but our surveys focused on the impact of 2 large randomized clinical trials on physician treatment practices for ICAS in the USA. We found significant differences in treatment choices for both medical and endovascular treatment of ICAS across the 3 surveys. While we found a tendency to adopt both medical and endovascular treatments supported by the clinical trial results, not all of the more effective treatment strategies in the trials were widely adopted.

Medical management of ICAS changed over the 3 study periods, which extended over more than a decade. After the publication of the WASID results, most neurologists preferred antiplatelet therapy over warfarin, and the preferred antiplatelet agent in the post-WASID survey was aspirin. However, despite the fact that aspirin was the only antiplatelet agent tested in WASID, a surprising number of respondents in the post-WASID survey (more than half) preferred other antiplatelet agents or combinations of antiplatelet agents over aspirin. This finding may be due to studies that showed other antiplatelet regimens may have a role in preventing stroke in patients with large artery atherosclerosis $[12,13]$. The most commonly prescribed dose of aspirin in the post-WASID survey was $325 \mathrm{mg} /$ day, despite the fact that the dose used in WASID was $1,300 \mathrm{mg} /$ day [14]. A stroke prevention guideline statement published around the time of the post-WASID survey [2006] recommended aspirin doses of $50-325 \mathrm{mg} /$ day in patients with atherosclerotic stroke or transient ischemic attack based on general safety and efficacy data [15], suggesting that our survey results regarding the aspirin dose are consistent with consensus expert opinion at the time.

Intracranial Stenosis Treatment

Preferences Survey
The neurologists' preference for dual antiplatelet (aspirin and clopidogrel) therapy in patients with ICAS increased from the post-WASID to the post-SAMMPRIS surveys. This is likely because of the lower early recurrent stroke rates in SAMMPRIS (when patients were on a combination of aspirin and clopidogrel) compared to WASID historical controls taking either aspirin or warfarin [6]. Results from the CLAIR study also showed that combined aspirin and clopidogrel decreased the number of microembolic signals on transcranial Doppler ultrasound compared to aspirin alone in patients with recently symptomatic ICAS [16], further supporting the use of dual antiplatelet therapy for early recurrent stroke prevention in ICAS. However, despite the fact that in the SAMMPRIS trial dual antiplatelet therapy was only used for 90 days, almost equal numbers of respondents in the postSAMMPRIS survey recommended dual antiplatelet therapy for 90 days (45\%) and indefinitely (44\%). So, in both the post-WASID and post-SAMMPRIS surveys it appears that the general selection of antithrombotic agents may be influenced by the clinical trial results, but that the specifics of the trial treatment protocols (e.g. specific antiplatelet agent or duration of treatment) were not strictly adopted.

The post-SAMMPRIS survey respondents' definitions of 'maximal medical management' included risk factor modification as a component, with only $4 \%$ of respondents indicating that 'failure of medical therapy' was limited to failure of antithrombotic agents alone. This finding probably reflects the respondents' recognition of the benefit of intensive risk factor management for improving the outcomes in medically treated patients in the SAMMPRIS trial compared to WASID historical controls [6] as well as previous analyses of WASID and SAMMPRIS data that have demonstrated that 'failure of antithrombotic therapy' is not a useful predictor of increased risk of recurrent stroke in patients with ICAS $[17,18]$.

While the majority of neurologists recommend PTAS in $<10 \%$ of their patients with ICAS in all survey periods, the percentage of neurologists who recommended PTAS in $>10 \%$ of patients significantly increased from the preto the post-WASID surveys. This finding is consistent with a retrospective study that showed an increase in intracranial PTAS procedures after the publication of the WASID results [19]. The increased frequency of endovascular procedures for ICAS after WASID, despite a lack of evidence for their efficacy for stroke prevention, may have reflected a perceived failure of medical therapies given the high risk of recurrent stroke in WASID and the availability of the Wingspan stenting system that was approved by the Food and Drug Administration under a humanitarian

Cerebrovasc Dis 2014;37:203-211 
device exemption (August 3, 2005). However, in the postSAMMPRIS survey, the percentage of neurologists who recommended PTAS in $>10 \%$ of patients returned to preWASID levels, likely due to the early SAMMPRIS results that showed no benefit from PTAS [6].

The post-WASID and post-SAMMPRIS surveys asked respondents what benefit they would require from endovascular procedures (PTAS and a 'new endovascular procedure', respectively) over medical therapy to make the procedure their treatment of choice for ICAS. For carotid stenosis, the North American Symptomatic Carotid Endarterectomy Trial (NASCET) [20] showed that the 2-year risk of ipsilateral stroke in patients with symptomatic extracranial carotid stenosis was $26 \%$ with medical therapy and $9 \%$ with surgical therapy, resulting in an NNT with endarterectomy of 6 patients. In our survey of ICAS treatment preferences, for a risk of stroke on medical therapy similar to NASCET ( $25 \%$ at 2 years), the majority of our respondents required an NNT of 13 patients to make an endovascular procedure the treatment of choice over medical therapy. This finding suggests that physicians may incorporate the risk/benefit ratio of established stroke prevention interventions into their expected benefits of procedures or they may have an inherent threshold for benefit that they feel is optimal for similar highrisk conditions. As expected, the RRR from PTAS and the 'new endovascular procedure' required by our survey respondents increased as the proposed risk of stroke on medical therapy decreased. In other words, as the rates of recurrent stroke with medical therapy decrease, the respondents require a much larger benefit from ICAS endovascular procedures to make the procedures their treatment of choice.

One of the reasons why we undertook the post-WASID survey was to help design the SAMMPRIS trial [21]. Historically, the hypothesized benefit of one treatment over another in many trials has been selected by estimating the treatment effect that physicians and patients would deem important to adopt a new treatment and by considering the feasibility of recruiting the required sample size. We chose to quantify the minimum benefit from PTAS that would make it the treatment of choice by surveying physicians who take care of patients with ICAS. The use of physician surveys may provide a more scientific approach for determining the clinically meaningful benefit that physicians will require to adopt a new treatment, thereby increasing the impact of clinical trials on clinical practice.

Our study has some weaknesses, including the practice type and experience differences between the pre- and post-WASID survey respondents. The post-WASID sur- vey included more university-based respondents than the other surveys, but the majority of respondents were at university centers in all 3 surveys. Additionally, we did not survey a random sample of physicians who take care of patients with ICAS, and we limited the survey to physicians in the USA. Given that the approach to patients with intracranial stenosis varies in different countries such as China [22], our results may not be representative of physicians who treat patients with ICAS worldwide. Finally, our survey data are self-reported and therefore subject to the inherent biases of such data, such as social desirability bias and recall bias.

In summary, our study shows that after the publications of the NIH-funded WASID and SAMMPRIS trials, there was a significant change in physician self-reported medical and endovascular treatment practices for ICAS in the USA. Based on these results, we expect that future clinical trials to determine the best management of patients with ICAS will likely have a significant impact on physician practices.

\section{Acknowledgments}

The authors wish to thank Diana Barrett for her administrative support for the post-SAMMPRIS survey and manuscript preparation. The WASID trial was supported by the National Institute of Neurological Disorders and Stroke (NINDS; R01NS36643). T.N.T., M.J.L., G.C., S.S., B.J.S. and M.I.C. have received funding from a research grant (U01NS058728) from the NINDS for the SAMMPRIS trial. The use of the REDCap survey tool was supported by the NIH (NCATS UL1TR000062).

\section{Disclosure Statement}

T.N.T. receives funding from the NINDS for research on intracranial stenosis (K23NS069668), B.J.S. receives funding from the NINDS for the Neurological Emergencies Treatment Trial Network, M.I.C. received funding from the NINDS for WASID (R01NS36643) and other research on intracranial stenosis (K24 NS050307 and R01NS051688); R.H.W., M.J.L., G.C., J.E.W. and S.S. have no relevant conflicts to report.

References

\footnotetext{
1 Sacco RL, Kargman DE, Zamanillo MC: Raceethnic differences in stroke risk factors among hospitalized patients with cerebral infarction: the Northern Manhattan Stroke Study. Neurology 1995;45:659-663.

$\checkmark 2$ Gorelick P, Wong K, Bae H, Pandey D: Large artery intracranial occlusive disease, a large worldwide burden but a relatively neglected frontier. Stroke 2008;39:23962399.
} 
-3 Chimowitz MI, Kokkinos J, Strong J, Brown MB, Levine SR, Silliman S, Pessin MS, Weichel E, Sila CA, Furlan AJ, et al: The warfarin-aspirin symptomatic intracranial disease study. Neurology 1995;45:1488-1493.

4 Caplan L, Babikian V, Helgason C, Hier DB, DeWitt D, Patel D, Stein R: Occlusive disease of the middle cerebral artery. Neurology 1985 ; 35:975-982.

5 Chimowitz MI, Lynn MJ, Howlett-Smith H, Stern BJ, Hertzberg VS, Frankel MR, Levine SR, Chaturvedi S, Kasner SE, Benesch CG, Sila CA, Jovin TG, Romano JG; WarfarinAspirin Symptomatic Intracranial Disease Trial Investigators: Comparison of warfarin and aspirin for symptomatic intracranial arterial stenosis. N Engl J Med 2005;352:13051316.

-6 Chimowitz MI, Lynn MJ, Derdeyn CP, Turan TN, Fiorella D, Lane BF, Janis LS, Lutsep HL, Barnwell SL, Waters MF, Hoh BL, Hourihane JM, Levy EI, Alexandrov AV, Harrigan MR, Chiu D, Klucznik RP, Clark JM, McDougall CG, Johnson MD, Pride GL Jr, Torbey MT, Zaidat OO, Rumboldt Z, Cloft HJ; SAMMPRIS Trial Investigators: Stenting versus aggressive medical therapy for intracranial arterial stenosis. N Engl J Med 2011;365:993-1003.

7 Harris PA, Taylor R, Thielke R, Payne J, Gonzalez N, Conde JG: Research electronic data capture (REDCap) - a metadata-driven methodology and workflow process for providing translational research informatics support. J Biomed Informat 2009;42:377-381.

$\checkmark 8$ Turan TN, Lynn MJ, Nizam A, Lane B, Egan BM, Le NA, Lopes-Virella MF, Hermayer KL, Benavente O, White CL, Brown WV, Caskey MF, Steiner MR, Vilardo N, Stufflebean A, Derdeyn CP, Fiorella D, Janis S, Chimowitz MI: Rationale, design, and implementation of aggressive risk factor management in the Stenting and Aggressive Medical Management for Prevention of Recurrent Stroke in Intracranial Stenosis (SAMMPRIS) trial. Circ Cardiovasc Qual Outcomes 2012; 5:e51-e60.
-9 Masuhr F, Busch M, Einhaupl KM: Differences in medical and surgical therapy for stroke prevention between leading experts in North America and Western Europe. Stroke 1998; 29:339-345.

10 Goldstein LB, Bonito AJ, Matchar DB, Duncan PW, Samsa GP: US national survey of physician practices for the secondary and tertiary prevention of ischemic stroke: carotid endarterectomy. Stroke 1996;27:801-806.

11 Goldstein LB, Bonito AJ, Matchar DB, Duncan PW, DeFriese GH, Oddone EZ, Paul JE, Akin DR, Samsa GP: US national survey of physician practices for the secondary and tertiary prevention of ischemic stroke: design, service availability, and common practices. Stroke 1995;26:1607-1615.

12 Halkes PH, van Gijn J, Kappelle LJ, Koudstaal $\mathrm{PJ}$, Algra A: Aspirin plus dipyridamole versus aspirin alone after cerebral ischaemia of arterial origin (ESPRIT): randomised controlled trial. Lancet 2006;367:1665-1673.

13 Markus HS, Droste DW, Kaps M, Larrue V, Lees KR, Siebler M, Ringelstein EB: Dual antiplatelet therapy with clopidogrel and aspirin in symptomatic carotid stenosis evaluated using Doppler embolic signal detection: the Clopidogrel and Aspirin for Reduction of Emboli in Symptomatic Carotid Stenosis (CARESS) trial. Circulation 2005;111:22332240.

14 Warfarin-Aspirin Symptomatic Intracranial Disease Trial Investigators: Design, progress and challenges of a double-blind trial of warfarin versus aspirin for symptomatic intracranial arterial stenosis. Neuroepidemiology 2003;22:106-117.

15 Sacco RL, Adams R, Albers G, Alberts MJ, Benavente $\mathrm{O}$, Furie K, Goldstein LB, Gorelick P, Halperin J, Harbaugh R, Johnston SC, Katzan I, Kelly-Hayes M, Kenton EJ, Marks M, Schwamm LH, Tomsick T: Guidelines for prevention of stroke in patients with ischemic stroke or transient ischemic attack. Circulation 2006;113:e409-e449.
16 Wong KSL, Chen C, Fu J, Chang HM, Suwanwela NC, Huang YN, Han Z, Tan KS, Ratanakorn D, Chollate P, Zhao Y, Koh A, Hao Q, Markus HS: Clopidogrel plus aspirin versus aspirin alone for reducing embolisation in patients with acute symptomatic cerebral or carotid artery stenosis (CLAIR study): a randomised, open-label, blindedendpoint trial. Lancet Neurol 2010;9:489497.

17 Turan TN, Maidan L, Cotsonis G, Lynn MJ, Romano JG, Levine SR, Chimowitz MI: Failure of antithrombotic therapy and risk of stroke in patients with symptomatic intracranial stenosis. Stroke 2009;40:505-509.

18 Lutsep H, Barnwel LS, Larsen D, Lynn M, Turan T, Lane B, Janis S, Derdeyn C, Fiorella $\mathrm{D}$, Chimowitz M: Outcome of patients in the SAMMPRIS trial who had failed antithrombotic therapy at study enrollment (abstract LB5). Stroke 2012;43(2). Also available at: http://my.americanheart.org/professional/ Sessions/InternationalStrokeConference/ Archive/ISC-2012-Late-Breaking-ScienceOral-Abstracts_UCM_435384_Article.jsp.

19 Moskowitz SI, Kelly ME, Obuchowski N, Fiorella D: Impact of WASID and Wingspan on the frequency of intracranial angioplasty and stenting at a high volume tertiary care hospital. J Neurointervent Surg 2009;1:165167

20 Beneficial effect of carotid endarterectomy in symptomatic patients with high-grade carotid stenosis. N Engl J Med 1991;325:445453.

-21 Chimowitz MI, Lynn MJ, Turan TN, Fiorella D, Lane BF, Janis S, Derdeyn CP: Design of the Stenting and Aggressive Medical Management for Preventing Recurrent Stroke in Intracranial Stenosis trial. J Stroke Cerebrovasc Dis 2011;20:357-368.

22 Liu X, Xiong Y, Zhou Z, Niu G, Wang W, Xiao G, Lin M, Leung TW, Liu D, Liu W, Fan X, Yin Q, Zhu W, Ma M, Zhang R, Xu G: China interventional stroke registry: rationale and study design. Cerebrovasc Dis 2013;35:349354
Intracranial Stenosis Treatment Preferences Survey
Cerebrovasc Dis 2014;37:203-211 DOI: $10.1159 / 000358120$ 